\title{
Factors and motives of unsafe behaviors of road users
}

\author{
H. Boudrifa, A. Bouhafs, M. Touill and F. Tabtroukia \\ Laboratory of Prevention \& Ergonomics, University of Algiers, Algeria. \\ Phone \& Fax: +21321941943 / E-mail:prevention_ergonomics@hotmail.com
}

\begin{abstract}
A questionnaire to measure factors and motives of unsafe behaviors of road users was constructed. This study tool was applied on a final sample of 5586 drivers in twelve out of forty eight districts in Algeria. The aim of the present study was to sort out the different factors and motives that make road users opt for the unsafe behaviors. The latter were determined mainly on the results of a previous study carried out on a final sample of 7058 drivers in twelve out of forty eight districts in Algeria in order to find the most frequent and dangerous unsafe behaviors of road users. The main unsafe and dangerous behaviors were then used in the present study. Friedman ranking means test was applied to rank the factors and motives selected under each unsafe behavior of road users. The whole results were summarised in seven axes of factors and motives causing: dangerous manoeuvrings by drivers, aggressive behaviors by drivers, negligence and ignorance of maintenance principals by drivers, lack of responsibility and engagement by drivers, cyclists and motorcyclists and their companions, as well as pedestrians and workers of road maintenance. The results are discussed in view of the previous studies and many recommendations have been made.
\end{abstract}

Keywords: unsafe behavior, Factor, motive, Road users, Road accidents.

\section{Introduction}

Despite the mobilization of many official and unofficial institutions to increase consciousness about the danger of road in order to promote public awareness about education and culture of road safety, and despite the introduction of two new rigorous laws in $2004 \& 2009$, as well as the execution of the technical control on vehicles, the number of road accidents and its victims are increasing as is shown in table 1. This situation has become a dilemma for the Algerian government especially with the big increasing number of vehicles and fast developments and changes that Algeria is going through, so this growing problem is not limited only to the number of injured and victims, but also has its drawbacks on the economical and social activities in general and the control of road traffic in particular.

In the same context, a previous study [4] found that $92.5 \%$ of drivers explain the non respect of traffic law by the lack of road education and culture, and $86.4 \%$ relate it to the lack of learning to drive, while $85.9 \%$ refer to the fact that the drivers rely on their personal relation to escape from sanction. This attitude is also confirmed by $85.2 \%$ of individuals of the study sample who point out the lack of rigorous application of sanctions on drivers who do not respect the Highway Code. In addition, $84.5 \%$ referred to drivers risk taking and adventures, $75.9 \%$ believe that the traffic law will never be applied, while $75.2 \%$ think that there will be a kind of tolerance according to the social status of the driver, the sex and the type of the vehicle. The question should therefore be raised on what are the factors and motives of unsafe

\footnotetext{
1 This research project is carried out for the benefit of: Centre National de la Prévention et la Sécurité Routière, Ministère des Transport,
} Algeria. 
behaviors of road users? To answer this question one needs to know or determine what are called unsafe behaviors of road users in a scientific way before looking for the factors and motives behind them.

One recent study [5] used a check-list of 150 items to measure unsafe behaviors of road users based on the third person principle. This study tool was applied on a final sample of 7058 drivers in twelve out of forty eight districts in Algeria. Subjects were asked to mark both the frequency and the degree of danger of each behavior (item) on two different scales of five points. The results were used to classify the 150 items in descending order in terms of their means for their frequency and their degree of danger. It was found that the frequencies of unsafe behaviors are not limited to the driver only, but expanded to cover all road users. It was concluded from the high values of means that drivers realise the danger of unsafe behaviours well, despite the fact that they do not respect the traffic rules and laws in reality. Moreover, to combine the frequency and the degree of danger, the results were treated by using a syntax program on the SPSS package to develop a matrix of nine categories of road users' behaviors after reducing the results on both scales to only three points for each. It was then possible to obtain the distribution of all these behaviors on the nine combinations of the matrices, but most items that had high scores were mainly on the following three categories:

1. Frequent and dangerous behaviors,

2. Average frequent and dangerous behaviors

3. Less frequent and dangerous behaviors.

An other study found that the problem of road safety depends on changing dangerous behaviors of drivers [8] and this change depends itself on the awareness and perception of those drivers of all dangers of road and driving, and that this awareness represents a principle condition for safe behavior in traffic movement in the society [11]. It has also been indicated that such unsafe or dangerous behaviors are only social positions that were not a good stimulus to these behaviors as it is related in strong relation with social environment to which the individual belongs and lives [1].

\section{Method}

\subsection{Study Tool}

A questionnaire to measure factors and motives of unsafe behaviors of road users was constructed. This study tool was applied on a final sample of 5586 drivers in twelve out of forty eight districts in Algeria.

Table 1

Statistics of the corporal accidents in four years.

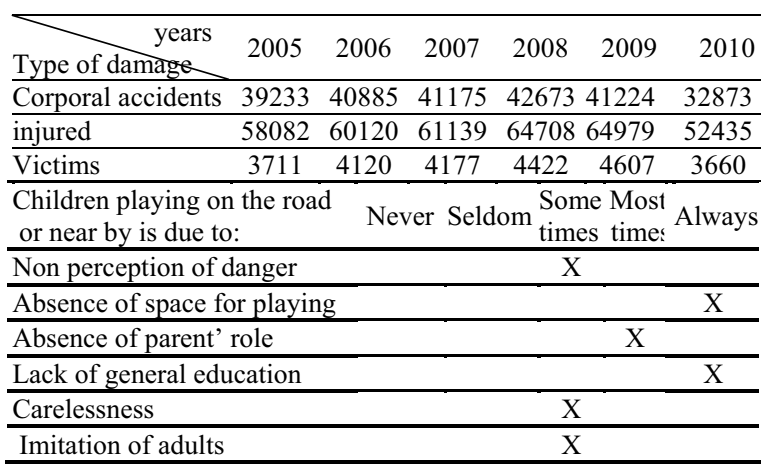

Twenty nine unsafe behaviors were selected to be used in the present questionnaire after many pilot studies. In this present paper only thirteen unsafe behaviors will be dealt with as examples. Each unsafe behavior selected was followed by a number of different factors and motives as items used after carrying a series of interviews among drivers as well as a preliminary study, in which an open choice question was added to give subjects the chance to add other factors or motives they thought were behind each behavior. Subjects were asked to mark their choice for each item on a five points scale (never, rarely, sometimes, most times, always). The following example shows factors and motives which make children play in the road or near by.

\subsection{Procedure}

Twelve out of 48 districts were chosen according to their order based on percentages of corporal accidents committed to the number of vehicles in each district. The geographical distribution was also taken into consideration by selecting each first three districts from the east, middle, west and south of Algeria in order to have a distribution representing these different regions by choosing districts which do not share the same border to obtain a representative distribution of each region. Moreover, the means available and the time allocated to this study were taken into consideration. Thus, the whole sample of the study was limited to 6000 drivers distributed over the twelve districts. The number of individuals of the 
sample for each district was then sorted out by dividing the number of the whole sample by the whole number of corporals accidents multiplied by the number of accidents committed in each district. The questionnaire was written recto-verso in Arabic and French to make it easier for drivers to answer it with the language they master better. It should pointed out that factors in tables 3 to 15 , will be written in Italic

\subsection{Distribution of the Questionnaire}

6000 Questionnaires in total were distributed over the twelve districts as mentioned above and as shown in table: 3. In addition, a number of questionnaires were added to each district to compensate any expected lost or not valid ones during the application of the study, so the final number distributed were 6470 questionnaires (see table: 2). Their distribution was carried out mainly by postgraduate students, but also under graduate students studying in psychology or sociology under the supervision of professors or assistant professors and all of them were from the concerned district. They were all paid for this task. These applicants scattered in places where drivers are expected to have free time to answer the questionnaires; mainly bus and taxis stations, vehicles insurance companies, vehicles' technical control stations and workshops for maintenance and reparations.

Table 2

Choice and Distribution of the Questionnaire

\begin{tabular}{|c|c|c|c|c|c|c|c|}
\hline 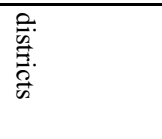 & 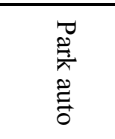 & $\begin{array}{l}\frac{b}{8} \\
\frac{0}{2} \\
\frac{0}{0} \\
\stackrel{\infty}{\infty}\end{array}$ & 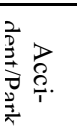 & 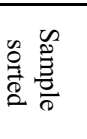 & 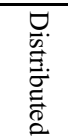 & 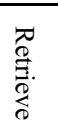 & 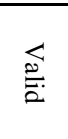 \\
\hline Alger & 812750 & 3425 & 0.42 & 1320 & 1350 & 179 & 1171 \\
\hline Sétif & 60762 & 2152 & 3.54 & 829 & 900 & 186 & 714 \\
\hline Telemcen & 101958 & 1560 & 1.53 & 601 & 620 & 58 & 562 \\
\hline Oran & 180966 & 1357 & 0.74 & 523 & 550 & 43 & 507 \\
\hline Oumelbouaki & 25997 & 1234 & 4.74 & 476 & 500 & 127 & 373 \\
\hline Chlef & 77264 & 1121 & 1.45 & 432 & 450 & 44 & 406 \\
\hline Bouira & 66830 & 1065 & 1.59 & 410 & 500 & 24 & 476 \\
\hline Médéa & 71771 & 963 & 1.34 & 371 & 400 & 101 & 299 \\
\hline Biskra & 44662 & 939 & 2.10 & 362 & 450 & 33 & 417 \\
\hline Annaba & 87874 & 723 & 0.82 & 279 & 300 & 31 & 269 \\
\hline Ourgla & 47632 & 696 & 1.46 & 268 & 300 & 36 & 264 \\
\hline Béchar & 19457 & 336 & 1.72 & 129 & 150 & 22 & 128 \\
\hline Total & 15979231 & 15571 & 21.45 & 6000 & 6470 & 884 & 5586 \\
\hline
\end{tabular}

\subsection{Statistical Technique Used}

The Statistical tests used in the present study are:

- Means and standards deviations to distribute the frequency factors or motives of unsafe behaviors of road users

- Friedman ranking means test was applied to rank the factors and motives selected under each unsafe behavior of road users

- The chi-square $\left(\chi^{2}\right)$ was also used to find out whether there are differences between subjects in their reaction to each item.

\section{Results}

\subsection{Axe one: Factors and motives causing dangerous maneuverings by drivers}

It can be noticed from table 3 , that there are many motives behind the unsafe behavior of overtaking in an unauthorized place. They indicate behaviors of risk taking and sensation seeking, in addition to few factors which do not seem to be objective, but rather as excuses as far as overtaking is not allowed in these places. However, this does not exclude the remainder of these factors like traffic jam and bad road design which may well contribute to the appearance of this unsafe behavior. It is therefore necessary to work on the best organization of the high way traffic movement besides applying scientific norms of road design and raising the level of awareness and road education.

Table 3

Factors and motives behind overtaking by a driver in non authorised place

\begin{tabular}{|c|c|c|c|}
\hline $\begin{array}{l}\text { Overtaking by a driver in non authorised place } \\
\text { is due to: }\end{array}$ & Mean & SD & $\begin{array}{l}\text { Rank } \\
\text { Means }\end{array}$ \\
\hline Over self confidence in the control of the vehicle & 3,57 & 1,091 & 11,66 \\
\hline Anxiety & 3,51 & 1,074 & 11,34 \\
\hline Non perception of danger & 3,46 & 1,151 & 11,16 \\
\hline Saving time & 3,49 & 1,206 & 11,13 \\
\hline The power and the type of vehicle & 3,43 & 1,114 & 10,88 \\
\hline Traffic jam & 3,39 & 1,091 & 10,64 \\
\hline Impulsion & 3,35 & 1,083 & 10,57 \\
\hline Imitation of other drivers & 3,27 & 1,076 & 10,18 \\
\hline An irrational decision & 3,29 & 1,189 & 10,18 \\
\hline Slowdown of vehicles in the front & 3,27 & 1,015 & 10,12 \\
\hline Rebellion & 3,24 & 1,129 & 10,07 \\
\hline Bad road design & 3,22 & 1,123 & 9,90 \\
\hline Self affirmation & 3,19 & 1,239 & 9,78 \\
\hline Stress of other drivers & 3,09 & 1,066 & 9,17 \\
\hline Believing in luck & 3,01 & 1,194 & 8,88 \\
\hline Ignorance of the traffic law & 2,96 & 1,212 & 8,83 \\
\hline Unrealistic optimism & 2,99 & 1,154 & 8,77 \\
\hline Minimising the danger of having an accident & 2,87 & 1,294 & 8,53 \\
\hline The wrong explanation of the traffic law & 2,85 & 1,178 & 8,22 \\
\hline
\end{tabular}

It appears from the results in table 4 , that there is a big series of motives related to the unsafe behavior of 
making dangerous manoeuvrings by drivers, which is headed by the motive of the weak perception and evaluation of the situation, followed by other motives like showing courage, exhibition of abilities in driving or saving time, ..etc, which emphasis the appearance of risk taking behaviors among drivers besides the coexistence of some negative social attitudes and beliefs that may help the appearance of this behavior, like attracting attention of others. Let alone the so many different factors that may strongly contribute in pushing the driver for risk taking when what might be imposed by the traffic jam and bad design of the road and its narrowness, and what could results from it as behaviors and stresses among drivers, besides the lack of strict application of traffic law.

Table 4

Making dangerous manoeuvrings by a driver

\begin{tabular}{|c|c|}
\hline $\begin{array}{l}\text { Making dangerous manoeuvrings by a driver is } \\
\text { due to: }\end{array}$ & Mean SD $\begin{array}{l}\text { Rank } \\
\text { Mean }\end{array}$ \\
\hline Weak perception and evaluation of the situation & $3,501,04214,09$ \\
\hline Intransigence & $3,511,08314,04$ \\
\hline Believing that traffic signals are not objective & $3,491,08213,99$ \\
\hline Showing courage & $3,471,08613,89$ \\
\hline Exhibition of driving competencies & $3,471,10113,89$ \\
\hline Saving time & $3,461,15913,85$ \\
\hline Lack of strict application of traffic law & $3,431,08813,63$ \\
\hline Attracting attention of others & $3,381,08013,16$ \\
\hline Over self confidence in the control of the vehicle & $3,371,06813,10$ \\
\hline Rebellion & $3,321,12412,86$ \\
\hline An irrational decision & $3,321,22412,84$ \\
\hline Bad organization of traffic movement & $3,281,05412,64$ \\
\hline Bad road design & $3,211,09912,27$ \\
\hline Slowdown of vehicles in the front & $3,241,00512,27$ \\
\hline Stress of other drivers & $3,191,02711,93$ \\
\hline Lack of awareness and road education & $3,171,13311,78$ \\
\hline Self affirmation & $3,151,25511,77$ \\
\hline Narrowness of the road & $3,161,05911,75$ \\
\hline Aggression & $3,161,14311,65$ \\
\hline Fatigue & $3,071,09111,34$ \\
\hline Believing that that traffic signal are non objective & $3,031,15311,18$ \\
\hline Believing in luck & $3,061,16811,16$ \\
\hline Unrealistic optimism & $3,021,153 \quad 10,98$ \\
\hline Minimising the danger of having an accident & $2,751,309 \quad 9,92$ \\
\hline
\end{tabular}

\subsection{Axe Two: Factors and motives causing aggression by drivers}

It can be concluded from table $5 \& 6$, that most motives point to the social side which is related to predominant bad attitudes, beliefs, habits and customs headed by the lack of civism in the society, that relies on the use of force when dealing with other road users. This thing might be behind the emergence of the aggressive as well as risk taking behaviors among drivers of buses and lorries in particular and other drivers in general. In addition to an important series of factors which might reinforce these behaviors, especially the lack of tolerance and cooperation among drivers, the power and the type of vehicle, lack of strict application of traffic law, bad organization of traffic movement and narrowness of the road. Hence, there is an absolute need to work on raising the level of civic sense, of civilised behaviors le level of tolerance and cooperation among drivers, as well as getting rid of many bad and negative attitudes in driving, meanwhile enhancing and developing positive values with the reduction of the degree of selfishness and aggression.

Table 5

A bus or lorry driver who threaten a car

\begin{tabular}{lllll}
\hline A bus or lorry driver who threaten a car is due to: & Mean & $\begin{array}{r}\text { SD } \\
\text { Rank } \\
\text { Mean }\end{array}$ \\
\hline Lack of civism & 3,62 & 1,080 & 9,05 \\
\hline Lack of tolerance and cooperation among drivers & 3,56 & 1,053 & 8,77 \\
\hline Looking down among drivers & 3,50 & 1,054 & 8,59 \\
\hline Aggression & 3,47 & 1,112 & 8,48 \\
\hline The power and the type of vehicle & 3,44 & 1,072 & 8,30 \\
\hline Carelessness & 3,41 & 1,041 & 8,20 \\
\hline Non respect of other road users 'right & 3,40 & 1,059 & 8,14 \\
\hline Lack of strict application of traffic law & 3,39 & 1,095 & 8,11 \\
\hline Bad organization of traffic movement & 3,30 & 1,051 & 7,76 \\
\hline An irrational decision & 3,28 & 1,206 & 7,72 \\
\hline Narrowness of the road & 3,24 & 1,091 & 7,56 \\
\hline Selfishness & 3,25 & 1,172 & 7,52 \\
\hline The wrong explanation of the traffic law & 3,17 & 1,132 & 7,38 \\
\hline Self affirmation & 3,15 & 1,234 & 7,25 \\
\hline As a reaction to other drivers' behaviours & 3,15 & 1,072 & 7,13 \\
\hline
\end{tabular}

Table 6

Incursion of a driver in a lane by force is due to:

\begin{tabular}{lrr}
\hline Incursion of a driver in a lane by force is due to: & Mean SD & $\begin{array}{c}\text { Rank } \\
\text { Mean: }\end{array}$ \\
\hline Non perception of danger & $3,541,118$ & 8,92 \\
\hline Over self confidence in the control of the vehicle & $3,541,039$ & 8,83 \\
\hline Carelessness & $3,501,031$ & 8,67 \\
\hline Lack of tolerance and cooperation among drivers & $3,481,030$ & 8,64 \\
\hline Traffic jam & $3,451,048$ & 8,46 \\
\hline The power and the type of vehicle & $3,421,042$ & 8,39 \\
\hline Selfishness & $3,431,082$ & 8,36 \\
\hline Lack of strict application of traffic law & $3,411,097$ & 8,25 \\
\hline Opportunism & $3,401,029$ & 8,22 \\
\hline An irrational decision & $3,391,151$ & 8,17 \\
\hline Believing in luck & $3,191,137$ & 7,46 \\
\hline Selfishness & $3,181,198$ & 7,40 \\
\hline Unrealistic optimism & $3,091,114$ & 6,98 \\
\hline The wrong explanation of the traffic law & $3,011,166$ & 6,75 \\
\hline Minimising the danger of having an accident & $2,841,304$ & 6,51 \\
\hline
\end{tabular}




\subsection{Axe three: Factors and motives causing negligence and ignorance of maintenance principals by drivers}

Although, the results in tables $7 \& 8$, showed very logical factors to a certain extent as far as it reflects the economical, social, and cultural difficulties that face the Algerian individual when he owns a vehicle and what follows that such as maintenance expenses that are beyond his financial means, it can also be extracted that the behavior of carrying a load not fixed or covered and driving a vehicle despite the coexistence of a mechanical defect are related to a big series of motives that reflect the whole unsafe behaviors which indicate the lack of road safety education among drivers together with the coexistence of a few contributory factors for the development of this phenomenon, as it is the case for lack of strict application of traffic law, the insufficient coexistence of the public order agents on the road, lack of material means and especially the ignorance of traffic law. It is therefore necessary to raise the driver' awareness about the effect and danger of all these types of unsafe behaviors and intensifying control of this kind of infringement in order to change the motives and factors behind negligence and ignorance of all types of maintenance principals.

Table 7

Driver carrying a load not fixed or covered

\begin{tabular}{|c|c|}
\hline $\begin{array}{l}\text { driver carrying a load not fixed or not covered is } \\
\text { due to: }\end{array}$ & Mean SD $\begin{array}{l}\text { Rank } \\
\text { Mean }\end{array}$ \\
\hline Negligence & $3,681,06310,88$ \\
\hline Carelessness & $3,631,07810,63$ \\
\hline Non perception of danger & $3,501,13210,22$ \\
\hline Impulsion & $3,451,107 \quad 9,88$ \\
\hline Lack of strict application of traffic law & $3,411,086 \quad 9,71$ \\
\hline An irrational decision & $3,311,207 \quad 9,25$ \\
\hline Expectation of non incurrence to an infringement & $3,271,072 \quad 9,13$ \\
\hline The insufficient coexistence of public order agent & $3,231,124 \quad 8,94$ \\
\hline Believing in luck & $3,161,185 \quad 8,62$ \\
\hline Lack of material means & $3,111,125 \quad 8,54$ \\
\hline Ignorance of traffic law & $3,091,132 \quad 8,45$ \\
\hline forgetfulness & $3,081,134 \quad 8,41$ \\
\hline Unrealistic optimism & $3,111,161 \quad 8,41$ \\
\hline Saving time & $3,071,223 \quad 8,27$ \\
\hline Non recognition of traffic law & $3,051,166 \quad 8,19$ \\
\hline Self affirmation & $2,991,247 \quad 7,95$ \\
\hline Minimising the danger of having an accident & $2,821,310 \quad 7,53$ \\
\hline
\end{tabular}

Table 8

Driving a vehicle with a mechanical defect.

\begin{tabular}{|c|c|}
\hline $\begin{array}{l}\text { Driving a vehicle with a mechanical defect is due } \\
\text { to: }\end{array}$ & Mean SD $\begin{array}{l}\text { Rank } \\
\text { Mean }\end{array}$ \\
\hline High cost of spare parts & $3,561,110 \quad 9,27$ \\
\hline
\end{tabular}

\begin{tabular}{lrr}
\hline Carelessness & $3,541,149$ & 9,16 \\
\hline The available spare parts are not original & $3,381,090$ & 8,56 \\
\hline Lack of awareness and road education & $3,351,092$ & 8,47 \\
\hline Lack of material means & $3,311,085$ & 8,22 \\
\hline Bad road condition & $3,281,110$ & 8,20 \\
\hline Unrealistic optimism & $3,291,182$ & 8,19 \\
\hline Ignorance of the mechanical side of the car by the drivel $3,271,046$ & 8,16 \\
\hline Non perception of danger & $3,241,207$ & 8,02 \\
\hline Lack of training in driving & $3,191,074$ & 7,84 \\
\hline Time shortage & $3,101,163$ & 7,60 \\
\hline Believing in luck & $3,111,185$ & 7,53 \\
\hline Unrealistic optimism & $3,061,149$ & 7,31 \\
\hline Self affirmation & $2,921,250$ & 6,90 \\
\hline Minimising the danger of having an accident & $2,761,323$ & 6,56 \\
\hline
\end{tabular}

\subsection{Axe four: Factors and motives causing lack of} responsibility and engagement by drivers

The results in tables $9 \& 10$, showed that there are so many different motives behind the lack of responsibility and engagement of the drivers which reflect the behavior of risk taking; the non feeling of the social responsibility in particular and the internal and external exigencies which the individual is exposed to in modern life in general, besides other factors that are not less important than those motives. They might even enhance the latter's as is the case of the factor of the power and the type of vehicle. In general, many studies have found that dangerous behaviors that are followed by drivers are referred to cultural elements learned in an indirect way, especially through the public media [6].

Table 9

Drivers exceed the speed limit.

\begin{tabular}{|c|c|}
\hline Exceed the speed limit by drivers is due to: & $\begin{array}{lll}\text { Mean SD } & \begin{array}{l}\text { Rank } \\
\text { Mean }\end{array} \\
\end{array}$ \\
\hline saving time & $3,571,206 \quad 12,77$ \\
\hline Non perception of danger & $3,511,160 \quad 12,71$ \\
\hline The power and the type of vehicle & $3,541,07712,71$ \\
\hline Pleasure and sensation seeking & $3,531,061 \quad 12,68$ \\
\hline Carelessness & $3,521,095 \quad 12,55$ \\
\hline Emptiness of the road & $3,511,119 \quad 12,46$ \\
\hline Exhibition of driving competencies & $3,481,068 \quad 12,37$ \\
\hline Attracting attention of others & $3,48 \quad 1,070 \quad 12,34$ \\
\hline Over self confidence in the control of the vehicle & $3,48 \quad 1,078 \quad 12,32$ \\
\hline A habit & $3,441,021 \quad 12,05$ \\
\hline The good knowledge of the path & $3,401,060 \quad 11,82$ \\
\hline An irrational decision & $3,371,192 \quad 11,68$ \\
\hline Lack of strict application of traffic law & $3,361,131 \quad 11,66$ \\
\hline Selfishness & $3,351,09611,61$ \\
\hline The fact that every body drives fast & $3,311,079 \quad 11,33$ \\
\hline Selfishness & $3,21 \quad 1,232 \quad 10,85$ \\
\hline The inattention & $3,221,072 \quad 10,83$ \\
\hline Believing in luck & $3,111,161 \quad 10,25$ \\
\hline Unrealistic optimism & $3,051,139 \quad 9,91$ \\
\hline Non recognition of traffic law & $2,991,204 \quad 9,70$ \\
\hline
\end{tabular}




\begin{tabular}{lll}
\hline Ignorance of the traffic law & $2,931,167$ & 9,36 \\
\hline Minimising the danger of having an accident & $2,781,319$ & 9,04 \\
\hline
\end{tabular}

Table 10

Not respecting the principle of priority

\begin{tabular}{lrrr}
\hline $\begin{array}{l}\text { Not respecting the principle of priority by } \\
\text { drivers is due to: }\end{array}$ & Mean & SD & $\begin{array}{r}\text { Rank } \\
\text { Mean }\end{array}$ \\
\hline Non feeling of the social responsibility & 3,45 & 1,091 & 11,07 \\
\hline Lack of awareness and road education & 3,42 & 1,098 & 10,91 \\
\hline Risk taking & 3,40 & 1,088 & 10,83 \\
\hline Saving time & 3,39 & 1,117 & 10,76 \\
\hline Selfishness & 3,39 & 1,092 & 10,70 \\
\hline Non respect of other road users & 3,38 & 1,050 & 10,67 \\
\hline Rebellion & 3,33 & 1,087 & 10,52 \\
\hline The wrong explanation to the right of priority & 3,33 & 1,055 & 10,47 \\
\hline The application of the priority to the strongest & 3,27 & 1,154 & 10,23 \\
\hline An irrational decision & 3,28 & 1,175 & 10,09 \\
\hline Difficulty in applying principle of priority in reality & 3,24 & 1,142 & 10,01 \\
\hline Tolerance of the public order agent & 3,20 & 1,079 & 9,74 \\
\hline Self affirmation & 3,16 & 1,216 & 9,58 \\
\hline Non existence of suitable traffic signals & 3,10 & 1,148 & 9,31 \\
\hline Believing in luck & 3,10 & 1,184 & 9,27 \\
\hline Non recognition of traffic law & 3,09 & 1,157 & 9,24 \\
\hline Ignorance of the traffic law & 3,06 & 1,163 & 9,13 \\
\hline Unrealistic optimism & 3,06 & 1,175 & 9,12 \\
\hline Minimising the danger of having an accident & 2,83 & 1,275 & 8,35 \\
\hline
\end{tabular}

\subsection{Axe five: Factors and motives causing lack of responsibility and engagement by cyclists and motorcyclists and their companions}

As can be noticed from table $11 \& 12$, there are various factors and motives behind unsafe behaviors of cyclists and motorcyclists and their companions. It seems that factors are well classified in this axe, which reflects the existence of lacking at many levels especially the non existence of a special path for them as a result of not taking this type of road users into consideration by road designers, besides the legislative gap concerning this category. This matter might pave the way for the development of the various motives shown in tables $11 \& 12$. However, this thing should not be an excuse for not respecting the high way code. It has even been found that some of the motorcyclists believe that there is a mysterious force that protects them and that's why they go for risk taking behaviors [6]. Hence, there is a need to work on raising their awareness and making them obey the safety rules of the high way code by intensifying the operations of awareness and road education as well as the strict application of traffic law on this category of road users, and why not the introduction of some adjustment on traffic law to cover any gaps related to this type of road users.
Moreover, It should be pointed out that this type of road users is usually limited to the category of youth and all what is related to it from unsafe behaviors like non perception of danger, especially when they are too young or did not have any training, which should be the responsibility of parents who buy these things for them and let them die on the road.

Table 11

Factors and motives that make cyclist and motorcyclist or their companions not wearing helmet.

\begin{tabular}{lrrr}
\hline $\begin{array}{l}\text { Not wearing helmet by cyclist and motorcy- } \\
\text { clist or their companions is due to: }\end{array}$ & Mean & SD & $\begin{array}{l}\text { Rank } \\
\text { Mean }\end{array}$ \\
\hline Carelessness & 3,64 & 1,088 & 10,49 \\
\hline Lack of awareness and road education & 3,51 & 1,106 & 9,98 \\
\hline Non perception of danger & 3,49 & 1,141 & 9,90 \\
\hline Lack of strict application of traffic law & 3,50 & 1,121 & 9,87 \\
\hline Showing courage & 3,45 & 1,131 & 9,79 \\
\hline Lack of training in driving & 3,37 & 1,110 & 9,39 \\
\hline Audacity & 3,39 & 1,222 & 9,35 \\
\hline An irrational decision & 3,37 & 1,199 & 9,33 \\
\hline Tolerance of the agent of order & 3,27 & 1,093 & 8,85 \\
\hline Ignorance of the traffic law & 3,18 & 1,199 & 8,70 \\
\hline Self affirmation & 3,17 & 1,267 & 8,55 \\
\hline Rebellion & 3,17 & 1,195 & 8,50 \\
\hline The non recognition of the high way code & 3,14 & 1,189 & 8,36 \\
\hline Believing in luck & 3,09 & 1,191 & 8,23 \\
\hline Saving time & 3,02 & 1,306 & 8,17 \\
\hline Unrealistic optimism & 3,08 & 1,165 & 8,14 \\
\hline Minimising the danger of having an accident & 2,79 & 1,354 & 7,39 \\
\hline
\end{tabular}

Table 12

Ccyclists and motorcyclists or their companions not respecting the high way code.

\begin{tabular}{|c|c|c|}
\hline $\begin{array}{l}\text { Not respecting the high way code by cyclist } \\
\text { and motorcyclist or their companions is due to: }\end{array}$ & Mean SD & $\begin{array}{l}\text { Rank } \\
\text { Mean }\end{array}$ \\
\hline Non existence of a special path for them & $3,611,140$ & 9,12 \\
\hline Carelessness & $3,581,093$ & 9,04 \\
\hline Lack of strict application of traffic law & $3,531,105$ & 8,87 \\
\hline Lack of awareness and road education & $3,481,080$ & 8,63 \\
\hline Selfishness & $3,401,270$ & 8,37 \\
\hline Lack of training in driving & $3,371,092$ & 8,17 \\
\hline Saving time & $3,331,162$ & 8,15 \\
\hline An irrational decision & $3,321,215$ & 8,03 \\
\hline Ignorance of the traffic law & $3,231,160$ & 7,82 \\
\hline Rebellion & $3,241,197$ & 7,71 \\
\hline Self affirmation & $3,211,242$ & 7,67 \\
\hline The non recognition of the high way code & $3,211,170$ & 7,60 \\
\hline Believing in luck & $3,111,171$ & 7,24 \\
\hline An irrational decision & $3,051,146$ & 6,97 \\
\hline Minimising the danger of having an accident & $2,841,313$ & 6,61 \\
\hline
\end{tabular}




\subsection{Axe six: Factors and motives causing lack of responsibility and engagement by pedestrians}

It can be noticed from tables $13 \& 14$, that there are various different motives and factors behind the unsafe behaviors of pedestrians, things that need intervention on many levels either by campaigns for awareness' raising in order to change wrong attitudes and beliefs acquired by pedestrians, or the role of the road designers in taking the necessary precautions either by giving pedestrian their right on the road or by putting design measures that could orient or direct their behaviors to use different pedestrian crossing as far as they rely on behavior of risk taking to cross the road and justify that by non objective excuses. In addition to the intervention of the legislature to introduce relevant laws that enforce the legislatives infringements that go with the degree of danger of behaviors for this category of road users.

It has been found that those pedestrians are more exposed to road accidents and that $41 \%$ to $75 \%$ of the total death among road users in the urban region are pedestrians [12]. Indeed, all factors and motives in tables $13 \& 14$, illustrate the vulnerability of pedestrians because of bad road design, absence of oriental barriers for them and especially ignorance of the traffic law, tolerance of the agent of public order and lack of awareness and road education. It is therefore expected to see the propagation of so many bad motives which help the appearance of unsafe behaviors among this type of road users. Hence, applying the ergonomics principles in the design of the road in general and the pavement in particular could not just direct the crossing and minimise unsafe behaviors of pedestrians, but also make life easier for so many other road users like those who need a daily use of wheelchairs or pushchairs. It is therefore possible to take into consideration all categories of road users with their own particularities not only as their right but also to avoid any conflict and especially to prevent road accidents and reduce the number of victims.

Table 13

Pedestrians crossing the road without respecting the orientation of the public order agent.

Pedestrians crossing the road without respecting Mean SD Rank the orientation of the public order agent Mean SD Mean Lack of strict application of traffic law on pedestrians 3,61 1,117 10,3C Difficulty in punishing them $3,521,1299,88$

\begin{tabular}{|c|c|}
\hline Lack of awareness and road education & $3,451,058 \quad 9,51$ \\
\hline saving time & $3,431,1229,50$ \\
\hline Traffic jam & $3,431,0679,48$ \\
\hline Over self confidence & $3,421,033 \quad 9,35$ \\
\hline Not paying attention & $3,401,032 \quad 9,32$ \\
\hline An irrational decision & $3,351,180 \quad 9,07$ \\
\hline Absence of oriental barriers for pedestrians & $3,341,0549,01$ \\
\hline Bad organization of traffic movement & $3,291,026 \quad 8,81$ \\
\hline Selfishness & $3,271,0958,69$ \\
\hline A habit & $3,251,1628,53$ \\
\hline Too many pedestrians on the pavement & $3,211,1128,37$ \\
\hline Self affirmation & $3,131,2058,13$ \\
\hline Bad road design & $3,141,0968,11$ \\
\hline Minimising the danger of having an accident & $2,861,3027,33$ \\
\hline
\end{tabular}

Table 14

Pedestrians crossing the road carelessly.

\begin{tabular}{lrrr}
\hline Crossing the road by pedestrian carelessly & Mear & $\begin{array}{l}\text { SD } \\
\text { Meank }\end{array}$ \\
\hline saving time & 3,56 & 1,155 & 11,45 \\
\hline Carelessness & 3,59 & 1,087 & 11,45 \\
\hline Non perception of danger & 3,53 & 1,134 & 11,28 \\
\hline Lack of strict application of traffic law on pedestrian & 3,55 & 1,150 & 11,28 \\
\hline Over self confidence & 3,49 & 1,068 & 10,97 \\
\hline Weak perception and evaluation of the situation & 3,41 & 1,051 & 10,51 \\
\hline Lack of concentration and attention & 3,41 & 1,039 & 10,50 \\
\hline Absence of oriental barriers for pedestrians & 3,40 & 1,069 & 10,48 \\
\hline Imitation of other pedestrians & 3,39 & 1,073 & 10,45 \\
\hline A habit & 3,34 & 1,195 & 10,10 \\
\hline An irrational decision & 3,31 & 1,197 & 10,10 \\
\hline Too many pedestrians on the pavement & 3,27 & 1,123 & 9,90 \\
\hline Bad road design & 3,26 & 1,094 & 9,78 \\
\hline Ignorance of the traffic law & 3,23 & 1,165 & 9,70 \\
\hline Believing in luck & 3,07 & 1,215 & 8,94 \\
\hline Selfishness & 3,07 & 1,136 & 8,93 \\
\hline Self affirmation & 3,05 & 1,222 & 8,86 \\
\hline Minimising the danger of having an accident & 2,75 & 1,276 & 7,81 \\
\hline Unrealistic optimism & 2,81 & 1,150 & 7,53 \\
\hline
\end{tabular}

3.7. Axe seven: Factors and motives causing lack of responsibility and engagement by workers of road maintenance

It can be noticed from table 15 , that there are many different motives behind not repairing the road. Most of them are related to work incentive for maintenance workers, the different sides of training and the lack of awareness about the importance of respecting the norms of road maintenance and work perfection, besides the weak level of taking full social and vocational responsibility by these workers. This matter needs rethinking about manners to raise the level of motivation and developing the feature of belonging to the institution. As for the factors, they seem to point out the organisational side of maintenance operation which require raising the level of competence among the staff in charge of maintenance in the field of communication and management of human and mate- 
rial resources, in addition to providing the necessary means, choosing the right time for intervention and respecting the norms and principles of road maintenance including the quality of materials used.

Table 15

Factors and motives that make maintenance workers not repair the road.

\begin{tabular}{|c|c|}
\hline $\begin{array}{l}\text { Not repairing the road by maintenance workers } \\
\text { is due to: }\end{array}$ & Mear SD $\begin{array}{l}\text { Rank } \\
\text { Mean }\end{array}$ \\
\hline Carelessness & $3,611,16311,09$ \\
\hline Negligence & $3,631,15511,07$ \\
\hline Absence of coordination between concerned services & $3,601,07911,07$ \\
\hline Not respecting maintenance' norms & $3,501,10810,61$ \\
\hline Bureaucracy & $3,471,20010,56$ \\
\hline Lack of skilled workers & $3,36 \quad 1,143 \quad 9,98$ \\
\hline Non perception of danger & $\overline{3,33 \quad 1,212 \quad 9,96}$ \\
\hline Lack of training & $3,28 \quad 1,117 \quad 9,72$ \\
\hline Traffic jam & $3,24 \quad 1,226 \quad 9,65$ \\
\hline An irrational decision & $3,261,246 \quad 9,56$ \\
\hline No respect to the right of the rest of road users & $3,23 \quad 1,154 \quad 9,36$ \\
\hline The Stress of the rest of road users & $3,15 \quad 1,106 \quad 9,19$ \\
\hline Lack of human and materials means & $3,05 \quad 1,273 \quad 8,99$ \\
\hline Lack of the will to work & $3,06 \quad 1,185 \quad 8,47$ \\
\hline A lot of work & $2,93 \quad 1,213 \quad 8,40$ \\
\hline Minimising the danger of having an accident & $2,88 \quad 1,321 \quad 8,23$ \\
\hline Not providing security outside working hours & $2,86 \quad 1,209 \quad 7,75$ \\
\hline Time Shortage & $2,66 \quad 1,232 \quad 7,34$ \\
\hline
\end{tabular}

\section{Discussion}

It can be noticed that factors and motives are different from one unsafe behavior to another and that even the rank means of the same factor or motif changes from one unsafe behavior to another. Moreover, although most unsafe behaviors are affected by both factors and motives, it is clear that some of them are mainly affected by factors while others by motives. Perhaps, what might be the most important thing shown by the results of the present study is that each unsafe behavior is affected by so many factors and motives which go well with the system approach that relies on the interaction of many factors that cause accident injuries. It is now known that accidents are the results of the interaction between many factors and that errors committed by the road users are only part of these factors.

Furthermore, it seems that there are so many factors which are supposed to play the role of normotive control of behavior as is the case for the lack of strict application of traffic law, the insufficient coexistence of public order agent, non existence of suitable traffic signals, traffic jam and absence of oriental barriers for pedestrians. They became as incentives for the emergence of many motives, if not originally behind their appearance, or in other word to prepare the suitable environment for them. This was named by many researchers as beliefs about the existence of some factors that may facilitate or complicate the performance of certain behaviors which were called by some researchers control beliefs [2, 3, 9, 7].

Hence, it can be concluded that it is possible to change or direct unsafe behaviors of road users by various means or strategies and through different stages. For example, improving conception of pavement and pedestrian crossings and adapting them to the required norms may well convince at least the majority of them to use these facilities in the appropriate way. The same thing could be done for drivers by good conception of road and traffic signs...etc.

Moreover, It is useful to emphasize on the importance of time and develop its management in the field of road traffic, as well as to take all necessary actions to promote road traffic system by appropriate planning of roads and introducing all different traffic signs and facilities especially those concerning the urban transports which might insure flexibility in the flow of traffic. This can make road users regain selfconfidence to arrive to their target in a reasonable time.

There is a necessity to good and effective organisation of road traffic, adaptation of economical trade and social activities and the organisation of working hours with the necessary fluidity of road traffic in order to create and prepare the suitable environment for the application of traffic law and its effective incorporation in reality [8]. Modern methods and means should also be used to pass on the message of the high way code to all road users by convincing them that the law and policemen are there to protect them [10].

Finally, It seems that the best way to promote safe behaviors is the need to work on the best improvement of factors that were found behind so many unsafe behaviors like the lack of strict application of traffic law, bad road design, and therefore, applying the ergonomics principles in the design of the road in general and the pavement in particular, but also trying as much as possible to adjust most road structure to the daily local needs of all different road users taking into account their culture, social beliefs, habits, security, in addition to, environmental, economical, regional and social situations.

For example, before thinking about the design or redesign of any sort of pedestrian crossings, the road designer may need to carry a small study to know the 
characteristics of pedestrians who will use it together with their economical and social activities. It is therefore necessary to find out whether to opt for a foot bridge and what kind of foot bridge? Will it be suitable for all pedestrians? Can old people, people with wheelchairs or pushchairs use it easily? Would it be better to opt for a subway or a tunnel? And will all of them be safe to use? Most important of all will people use it or will they prefer to take the risk and cross the few meters of the road instead of using any type of pedestrian crossings? Perhaps the designer could opt for another solution, like a tunnel or bridge for vehicles and leave the straight way for pedestrians.

\section{References}

[1] Ajzen, I., \& Fishbein, M, understanding Attitudes and Predicting Social Behavior. Prentice-Hall, Englewood Cliffs, 1980.

[2] Ajzen, I. From intentions to actions: a theory of planned behaviour, in: Kuhl, J., Beckmann, (Eds), Action-Control: from Cognition to Behavior. Springer, Heidelberg, 1985

[3] Ajzen, I. Attitudes, personality, and behavior (2nd. Edition), 2005.
[4] Boudrifa. H, Tir. R, Boukabous, A, L'efficacité du nouveau code de la route dans la limitation des violations aux règles de la circulation. Revue de Prévention et d'Ergonomie, N0.1, Laboratoire de Prévention et d'Ergonomie, l'Université d'Alger. Dar El-Malakia for publication, Algiers, 2007.

[5] Boudrifa. H, A. Bouhafs, M. Touil1 \& F. Tabtroukia. Measurements Of Unsafe Behavior Of Road Users, 15th International Conference Road Safety on Four Continents, Abu Dhabi, United Arab Emirates, 28-30 March 2010

[6] Brunel, E,: L'insécurité routière, école national d'ergonomie de Saint-Etienne, France. De pelsmacker, P \& Janssens, w. 2007.

[7] Patrick De Pelsmacker \& Wim Janssens A, Model for Fair Trade Buying Behaviour: The Role of Perceived Quantity and Quality of Information and of Product-Specific Attitudes. Journal of Business Ethics 75 (4). 2007.

[8] Elvik R., "How much do road accidents cost the national economy?" Accident Analysis \& Prevention, 32: 849-851. 2002.

[9] Johnson S. E., Hall A, "The prediction of safe lifting behaviour". Journal of Safety Research, 36: 63-73. 2005.

[10] Horberry T., Anderson J., Regan M. A., Triggs T. J.., Brown J., "Driver distraction: the effects of concurrent in -vehicle tasks, road environment complexity and age on driving performance. Accident Analysis \& Prevention, 38:185-191. 2006.

[11] Vanlaar W., Yannis G., "Perception of road accidents causes". Accident Analysis \& Prevention, 38: 155-161, (2006).

[12] Yates \& stone, Risk Construct, in Risk Behavior, ibid. 1992. 